\title{
MANAGEMENT DYSPHAGIA IN POST-STROKE PATIENTS RECOMMENDATIONS FOR INDONESIAN NURSING INTERVENTION STANDARDS: A LITERATURE REVIEW
}

\author{
Syahrun $^{1}$, Alfrina Hany ${ }^{2}$, Masruroh Rahayu ${ }^{2}$ \\ Correspondence: syahrun@student.ub.ac.id \\ ${ }^{1}$ Brawijaya University, Student of Master Nursing, Faculty of Medicine, Malang, Indonesia \\ ${ }^{2}$ Brawijaya University, Lecturer in Master Nursing, Faculty of Medicine
}

\section{Article History: \\ Received: March 30, 2021 \\ Accepted: September 27, 2022 \\ Published: January 1, 2022}

\section{Cite this as:}

Syahrun S, Hany A, Rahayu M. Management dysphagia in poststroke patients recommendations for Indonesian nursing

intervention standards: A

literature review. Malang

Neurology Journal; 2022.8:39.

48. DOI:

http://dx.doi.org/10.21776/ub.mnj .2022 .008 .01 .9

\section{ABSTRACT}

Background: Dysphagia often occurs in post-stroke patients, causing aspiration that can result in disability or death. Nurses have an essential role to play in preventing these complications as they 24/7 care for patients. However, there is no written standard of nursing care regarding specific interventions of post-stroke dysphagia in reality.

Objective: The purpose of this article is to conduct a literature review of interventions that can be made in patients with post-stroke dysphagia so that it can be a recommendation for Indonesian nursing standards.

Design: Electronic literature searches PubMed, EBSCO (Medline), ProQuest, and ScienceDirect databases from January 2011 to October 2020. There was sixteen studies reviewed included in this systematic study were experimental, randomized controlled trials, or systematic reviews (which are also experimental designs, randomized controlled trials). The study focused on non-invasive interventions performed on post-stroke dysphagia patients.

Results: Interventions in dysphagia found, namely: The use of food thickeners against the risk of aspiration resulted in the patient's swallowing ability significantly increased by $71.9 \%(\mathrm{p}<0.01)$; Chin down intervention combined with thickening fluid provides a solution to improve the nutritional needs of patients dysphagia post-stroke; Tongue training interventions, swallowing training and speech therapy; Tongue stretching exercises that have a positive effect on tongue motility and oromotor function in post-stroke dysphagia patients; Intervention of Tongue resistance training that increases the strength of the tongue and reduces fluid residue in the vallecular; and early screening of dysphagia by nurses using formal guidelines to manage dysphagia patients thereby reducing chest infections and mortality.

Conclusion: Nurses should not diagnose dysphagia, but can identify post-stroke dysphagia to determine the interventions necessary for nutrition management, hydration, and aspiration prevention. Interventions include early dysphagia screening within 24 hours after stroke, thickening nutrition according to nutritionist recommendations, laryngeal elevation exercises, peripheral stimulation, posture regulation, and education on eating and drinking.

Keywords: Dysphagia nursing intervention, post-stroke dysphagia intervention, dysphagia in nursing

\section{Introduction}

Dysphagia is the difficulty of swallowing or removing food from the oral cavity into the stomach. Dysphagia is divided into odynophagia, pain when swallowing, and globus where a person feels a lump in the throat. ${ }^{1}$ Dysphagia is a common neurological symptom in stroke patients and results in increased post-stroke complications such as pneumonia due to cough reflex dysfunction and aspiration due to immunodepression resulting in two-thirds of sufferers that can result in death and disability. ${ }^{2}$

Dysphagia in stroke sufferers has significant consequences if not appropriately handled, $40-78 \%$ of people with dysphagia due to stroke can be completely cured but the rest will experience permanent dysphagia. ${ }^{3}$ The patient may require alternative means of nutrition, such as food hoses;
However, this does not necessarily improve quality of life (QOL) or prolong survival. Patients can remain dysphagic long after acute hospitalization and therefore require follow-up care long after discharge from the hospital. ${ }^{4}$

The role of nurses who are always on the patient's side is essential for the knowledge and understanding of nurses in preventing aspiration by identifying individuals with difficulty swallowing and initiating appropriate nursing interventions in the management of dysphagia. ${ }^{4}$

Dysphagia intervention in the nursing role is to identify individuals with difficulty swallowing and initiate interventions that can prevent further complications until a formal assessment can be carried out, as nurses are in an ideal position 24 hours a day in the hospital. ${ }^{5}$ While this depends on the family's knowledge in minimizing delays in 
arrival to the hospital to maximize effective treatment, which relates to risk factors and signs and symptoms. ${ }^{6}$

Dysphagia interventions are commonly performed by speech and language therapists, including modifying fluid and food consistency, postural techniques, swallowing exercises, and stimulation of oral and pharyngeal structures. ${ }^{7}$ In Indonesian Nursing Intervention Standards, dysphagia is included in the diagnosis of nursing swallowing disorders with the primary interventions selfcare support: Eating / Drinking or Prevention of Aspiration. ${ }^{8}$

The weakness in Indonesian nursing care intervention is the absence of special measures in dealing with swallowing disorders, as the focus of the intervention is on observation and monitoring. The study contains recommendations that can add evidence-based treatment practices to nursing interventions in patients with post-stroke dysphagia.

\section{Methods}

\section{Data sources}

The research method used in this paper is the literature review. To collect data, the author uses several databases namely Pubmed, EBSCO (Medline), ProQuest, and ScienceDirect.

\section{Search strategy}

The author also uses several search keywords namely "dysphagia nursing intervention", "post-stroke dysphagia intervention", and "dysphagia in nursing". Also searches are limited to articles containing full text from January 2011 to October 2020. These terminologies are used in combination so that the literature found is more specific.

\section{Inclusion criteria}

The article search inclusion criteria is (1) systematic review are experimental, randomized controlled trials, or systematic reviews (i.e. also experimental designs, randomized controlled trials) a discussion article about dysphagia intervention; (2) The study focused on noninvasive interventions performed on post-stroke dysphagia patients; (3) English-language articles with human subjects only.

\section{Results}

Due to significant heterogeneity in design and methodology, types of interventions used, and patients with dysphagia, 16 items were analyzed. (table 1).

The article consists of 3 items with systematic reviews, one narrative article review, one article case study, and 11 articles with experimental design. Based on the article that was reviewed in general, the interventions that can be done in dysphagia patients are conducting an early screening of dysphagia, conducting oral nurses, dietary modification with fluid and food thickeners, laryngeal elevation exercises, peripheral stimulation, positioning, and education of how to eat and drink well.

Articles on early screening of dysphagia by nurses and using formal guidelines can treat dysphagia patients to reduce chest infections and mortality ${ }^{9}$, As for oral nurses proven to reduce aspiration pneumonia. ${ }^{10,11}$
Modifying diet with thickeners of fluids and foods reduced the risk of aspiration and significantly improved swallowing ability in $71.9 \%$ of patients $(p<0.01) 12,13$ as a solution to the nutritional needs of dysphagia patients post stroke $^{14}$ including intervention challenge swallow $90 \mathrm{cc}$ of water. ${ }^{15}$

The following intervention is laryngeal elevation exercises with techniques used: Tongue exercise, swallowing training, and speech therapy ${ }^{16}$; Tongue Stretching that has a positive effect on tongue motility and oromotor function in post-stroke dysphagia patients ${ }^{17}$; Tongue resistance can increase the strength of the tongue and reduce fluid residue in the vallecular ${ }^{18}$; and Oral neuromuscular training. ${ }^{19}$

For intervention with electrical stimulation, among others with Resistance Expiratory Muscle Strength Training $(\text { EMST })^{19}$; Isometric progressive resistance oropharyngeal ${ }^{4}$; Electrical Stimulation. ${ }^{20}$ While intervention other is the position setting (position lying tilted, half sitting or sitting) depending on which position optimizes the swallowing ability of the patient ${ }^{21}$ as well as communication of dysphagia therapy through dietary arrangements when the patient returns home. ${ }^{21}$

\section{Discussion}

The This literature review contains sixteen articles on dysphagia interventions that recommend nurses provide interventions on Indonesian nursing care standards in poststroke dysphagia patients through cooperation with other health workers to improve positive outcomes in the hospital environment.

The approach to treating dysphagia reduces morbidity and mortality associated with pulmonary infections and poor nutritional status. Dysphagia therapy consists of compensation strategies to keep patients safe while eating and rehabilitation to speed up the recovery process. ${ }^{22}$

Management of dysphagia by nurses is effective in reducing chest infections, reducing hospitalization, time efficiency in early screening of dysphagia, lowering mortality rates, improving the knowledge of dysphagia patients within 24 hours, identifying clinical signs of dysphagia. ${ }^{9}$

Nurses need to be able to assess patients holistically to ensure that hydration and nutrition needs are met effectively and safely by paying attention to oral hygiene, and nutritional status is essential aspect in the treatment of dysphagia and ensuring the correct position of the patient when eating or drinking. ${ }^{23}$

Several actions can be recommended by nurses to be used as interventions in nursing care for dysphagia patients, among others:

\section{Dysphagia screening}

Dysphagia puts stroke patients at higher risk of developing pneumonia, disability, and death, while early screening for dysphagia results in a reduced risk of pneumonia and disability due to stroke. ${ }^{2}$ Early identification and treatment are crucial to minimizing the risk and effects of dysphagia, with early detection within 24 hours after stroke reducing pneumonia by 3 times. 
Table 1. Dysphagia intervention study in post-stroke patients

\begin{tabular}{|c|c|c|c|c|}
\hline Author and Year & Study Design & Population & Type of Intervention & Results / Conclusions \\
\hline $\begin{array}{l}\text { Yu Zhang } \\
\text { Xudong Jiang } \\
(2020)\end{array}$ & $\begin{array}{l}\text { Systematic } \\
\text { Review }\end{array}$ & Not explained & $\begin{array}{ll}\text { - } & \text { Transcranial } \\
\text { stimulation of } \\
\text { magnetic or } \\
\text { neurotransmitters } \\
\text { - } & \text { Acupuncture } \\
\text { - } & \text { Tongue training } \\
\text { - } & \text { Swallowing } \\
& \text { training } \\
\text { - } & \text { Speech therapy } \\
\end{array}$ & The main recommendations are not explained \\
\hline $\begin{array}{l}\text { Hwang, Kim, } \\
\text { Shim, \& Park, } \\
(2019)\end{array}$ & $\begin{array}{l}\text { Randomized } \\
\text { controlled trial }\end{array}$ & $\begin{array}{l}25 \text { post-stroke dysphagia } \\
\text { patients }\end{array}$ & $\begin{array}{l}\text { - } \quad \text { Tongue Stretching } \\
\text { Exercise (TSE) }\end{array}$ & $\begin{array}{l}\text { The experimental group showed significant results on } \\
\text { tongue motility, bolus formation, tongue to palate contact. } \\
\text { TSE positively affects tongue motility and oromotor } \\
\text { function in post-stroke dysphagia patients, so it is } \\
\text { recommended for effective dysphagia treatment. }\end{array}$ \\
\hline $\begin{array}{l}\text { 3. } \\
\text { Clave, } \\
\text { Lansink, } \\
\text { Bolivar- } \\
\text { Prados, } \\
\text { Mireia Laia } \\
\text { Rofes, } \\
\text { Viridiana } \\
\text { Arreola, } \\
\text { Sonia Guida, } \\
\text { Weslania V. } \\
\text { Nascimento et } \\
\text { al (2019) }\end{array}$ & $\begin{array}{l}\text { Experimental } \\
\text { control }\end{array}$ & $\begin{array}{l}120 \text { Dysphagia post stroke } \\
\text { patients }\end{array}$ & $\begin{array}{l}\text { Assess the safety } \\
\text { of food thickeners } \\
\text { against the risk of } \\
\text { aspiration }\end{array}$ & $\begin{array}{l}\text { As many as } 41.2 \% \text { of patients safely swallowed dilute } \\
\text { fluids, and } 71.9 \% \text { significantly increased the viscosity } \\
\text { given the thickener }(\mathrm{P}<0,01) \text {. } \\
\text { Increasing the bolus based on xanthan gum increases } \\
\text { swallowing safety in post-stroke dysphagia patients } \\
\text { without increasing pharyngeal residue. }\end{array}$ \\
\hline $\begin{array}{l}\text { 4. Jakobsen D, } \\
\text { Poulsen I, } \\
\text { Schultheiss C, } \\
\text { Riberholt CG, } \\
\text { Curtis DJ, } \\
\text { Petersen TH, } \\
\text { et al (2019) }\end{array}$ & $\begin{array}{l}\text { Randomised } \\
\text { controlled trial }\end{array}$ & $\begin{array}{l}10 \text { dysphagia with neurological } \\
\text { diagnosis (aneurism, } \\
\text { hypophysis adenoma infarction, } \\
\text { intracerebral hemorrhage, } \\
\text { meningioma, subarachnoid } \\
\text { hemorrhage, severe traumatic } \\
\text { brain injury }\end{array}$ & $\begin{array}{l}\text { Patients positioned } \\
\text { in side-lying, half } \\
\text { sitting or sitting, } \\
\text { depending on } \\
\text { which position } \\
\text { optimized the } \\
\text { patient's ability to } \\
\text { swallow }\end{array}$ & $\begin{array}{l}\text { The intensified intervention was feasible. Penetration } \\
\text { Aspiration Scale (PAS) and Functional Oral Intake Scale } \\
\text { (FOIS) scores improved in both groups, with no } \\
\text { differences between groups. The swallowing specific } \\
\text { parameters reflected clinically observed changes in } \\
\text { swallowing. } \\
\text { PAS and FOIS are feasible instruments to measure } \\
\text { dysphagia. It is possible and valid to measure swallowing } \\
\text { frequency and kinematics using electromyography and } \\
\text { bioimpedance. The definitive study should have widened } \\
\text { inclusion criteria and optimize intervention timing to } \\
\text { maintain patient arousal }\end{array}$ \\
\hline $\begin{array}{l}\text { Hägglund } \mathrm{P} \text {, } \\
\text { Hägg } \mathrm{M}, \\
\text { Wester P, } \\
\text { Levring JE } \\
\text { (2019) }\end{array}$ & $\begin{array}{l}\text { Cluster } \\
\text { randomized } \\
\text { controlled } \\
\text { study }\end{array}$ & $\begin{array}{l}385 \text { participants from the } \\
\text { intermediate care unit and } 116 \\
\text { participants randomly assigned }\end{array}$ & $\begin{array}{l}\text { - Oral neuromuscular } \\
\text { training }\end{array}$ & $\begin{array}{l}\text { At the end of treatment, the geometric mean of the } \\
\text { swallowing rate in the intervention group had significantly } \\
\text { improved } 60 \% \text { more than that of controls }(\mathrm{P}=0.007) \text {. At } 6 \\
\text { months post-treatment, the intervention group's swallowing } \\
\text { rate remained significantly better }(\mathrm{P}=0.031) \text {. Signs of } \\
\text { aspiration also significantly reduced in the intervention } \\
\text { group compared with controls }(\mathrm{P}=0.01) \text {. No significant } \\
\text { between-group differences were found for swallowing- } \\
\text { related QOL. }\end{array}$ \\
\hline
\end{tabular}

Oral neuromuscular training is a new promising swallowing rehabilitation method among older people in intermediate care with impaired swallowing.

Three weeks post-implementation, the oral care group had significant oral health improvements relative to the control

6. Hsiao-Jung

Chen, JeanLon Chen,

Chung-Yao Chen, Megan Lee, Wei-Han Chang and Tzu-Ting Huang (2019)

Randomised controlled trial

66 patients with stroke - Oral care group $(95 \% \mathrm{CI}=-2.69$ to -1.25 , Wald $\chi 2=29.02, \mathrm{p}<$ $0.001)$. There was no difference in the FOIS $(95 \% \mathrm{CI}$ $=-0.16$ to 0.89 , Wald $\chi 2=1.86, \mathrm{p}>0.05)$, MNA-SF $(95 \%$ $\mathrm{CI}=-0.35$ to 0.53 , Wald $\chi 2=-0.17, \mathrm{p}>0.05$ ), and nasogastric tube removal $(\mathrm{p}>0.05)$ between groups.

The oral care group had a higher but non-significant FOIS score $(3.94$ vs 3.52$)(p>0.05)$.

Routine oral health programs implemented during stroke rehabilitation in patients with dysphagia may promote oral health and maintain oral intake

There is no good evidence to date that thickening liquids reduce pneumonia in dysphagia and this intervention may be associated with reduced fluid intake. Texture-modified foods may contribute to undernutrition in those with dysphagia. Modified diets worsen the quality of life of those with dysphagia, and non-compliance is common.

7. O'Keeffe ST Narrative (2018)
Modifying diets by thickening liquids and modifying the texture of foods to reduce the risk of aspiration has become central to the current management of dysphagia
The disconnect between the limited evidence base and the widespread use of modified diets suggests the need for more careful consideration of when modified diets might be recommended to patients. Patients (or their representatives) have a choice whether or not to accept a modified diet. They must receive adequate information 


\begin{tabular}{|c|c|c|c|c|}
\hline 8. & $\begin{array}{l}\text { Mi-Ja Eom, } \\
\text { Moon-Young } \\
\text { Chang, Dong- } \\
\text { Hwan Oh, } \\
\text { Hyun-Dong } \\
\text { Kim, Na-Mi } \\
\text { Han and Ji-Su } \\
\text { Park (2017) }\end{array}$ & $\begin{array}{l}\text { Experimental } \\
\text { group }\end{array}$ & $\begin{array}{l}30 \text { stroke patients with } \\
\text { dysphagia }\end{array}$ & $\begin{array}{l}\text { Resistance } \\
\text { expiratory muscle } \\
\text { strength training } \\
\text { (EMST) }\end{array}$ \\
\hline 9. & $\begin{array}{l}\text { Steele CM, } \\
\text { Bayley MT, } \\
\text { Peladeau- } \\
\text { Pigeon M, } \\
\text { Nagy A, } \\
\text { Namasivayam } \\
\text { AM, Stokely } \\
\text { SL, et al, } \\
(2016)\end{array}$ & $\begin{array}{l}\text { Randomized } \\
\text { controlled trial }\end{array}$ & $\begin{array}{l}26 \text { post-stroke dysphagia } \\
\text { patients }\end{array}$ & $\begin{array}{l}\text { - Tongue resistance } \\
\text { exercises }\end{array}$ \\
\hline 10. & $\begin{array}{l}\text { Hines, } \\
\text { Kynoch, \& } \\
\text { Munday } \\
(2016)\end{array}$ & $\begin{array}{l}\text { Systematic } \\
\text { Review }\end{array}$ & $\begin{array}{l}15 \text { studies on managing } \\
\text { dysphagia effectively }\end{array}$ & $\begin{array}{l}\text { - Early screening by } \\
\text { nurses } \\
\text { - Guidelines for } \\
\text { formal dysphagia }\end{array}$ \\
\hline
\end{tabular}

about the potential risks and impact on the quality of life and the possible benefits to make that choice. There is an urgent need for better quality evidence regarding this intervention.

The experimental group showed more improvement in the pharyngeal phase of the Videofluoroscopic dysphagia scale (VDS) ( $\mathrm{p}=0.018$ and 0.006 , respectively) and penetration aspiration scale (PAS) compared to the placebo group $(\mathrm{p}=0.014)$.

EMST could improve the effects of dysphagia observed in post-stroke elderly patients based on swallowing function.

Experiments show that tongue strength can be improved by resistance training for individuals with a weak tongue after a stroke, but increased penetration and aspiration do not always accompany an increase in tongue strength However, these exercises are effective in reducing fluid residue in the vallecular.

Early screening for dysphagia by nurses in patients with acute neurological deficits is effective in improving patient outcomes. The existence of formal guidelines for the identification and management of dysphagia has a significant effect on chest infection and mortality.

Showed that a regimen of regular oral care and free water provision, when combined with dysphagia intervention, did prevent aspiration pneumonia in patients with oropharyngeal dysphagia.
11. Jaishika Quasi- Seedat, Claire experimental $\quad 32$ stroke patients, 14 patients Penn(2016) parallel group design

Oral care regimen
combined with free
water provision for
patients with
oropharyngeal
dysphagia

Oram care regimen

The article highlights two key findings: that regular and routine oral care is manageable within an acute government hospital context. A strict routine of oral care can reduce aspiration pneumonia in patients with oropharyngeal dysphagia.

An implication from these findings is confirmation that teamwork in acute care settings in developing contexts must be prioritized to improve dysphagia management and patient prognosis

Findings after 8 weeks of I-PRO therapy were progression to general oral diet, $15 \mathrm{lb}$ weight gain, increased isometric pressures $(\Delta>16 \mathrm{kPa})$ with transference to swallowing pressures, increased lingual volume $(8.3 \%)$, reduced pharyngeal wall residue $(\mathrm{P}=.03)$, increased pharyngeal pressures $(\Delta>43 \mathrm{~mm} \mathrm{Hg})$ and increased UES opening (nadir) pressures $(\Delta>9 \mathrm{~mm} \mathrm{Hg})$ with improved temp or pressure coordination across the pharynx, and improved QOL. After detraining, decreased isometric forces and reduced UES opening were noted. After I-PRO maintenance, isometric anterior lingual pressures returned to levels pointed out after the 8 weeks of intervention.

I-PRO therapy, facilitated by the Madison Oral Strengthening Therapeutic (MOST) device combined with instrumental UES dilatation, improved swallow safety, increased oropharyngeal intake and facilitated UES opening while enriching QOL
Isometric

oropharyngeal (I-

PRO) therapy

swallowing

function
711 patients with

parkinsonism and dementia

- 61 acute stroke patients

- 17 chronic dysphagia patient

- 31 dysphagia patient

91 acute stroke patients

- 26 chronic stroke patients

- 24 patients with acute poststroke dysphagia

13. Andersen,

Beck,

Kjaersgaard, Systematic

Hansen, \& Review

Poulsen,

(2013)
- 13 acute post-stroke

dysphagia patients

- 15 study in elderly patients with stroke dysphagia

- 18 studies in elderly patients at risk of aspiration

- 515 Parkinson's or dementia patients

- 56 chronic dysphagia patient

- 115 chronic dysphagia

patient

- 306 acute dysphagia patient

with stroke in hospital
Chin down procedures and thickening fluids are the main recommendations in chronic dysphagia cases to treat or prevent aspiration.

Meanwhile, in the acute phase, viscosity-modified food is one solution to improve nutrition. 
14. Park Jin-Woo, Youngsun Kim, JongChi Oh, HoJun Lee (2012)
A doubleblind, randomized, controlled study
20 post-stroke patients with dysphagia Stimulation

In the experimental group, the larynx's maximal vertical displacement was increased significantly after the intervention ( $p \backslash 0.05)$. The maximal vertical displacement of the hyoid bone and the UES opening's maximal width increased but the increase was not found to be significant $(\mathrm{p}=0.066)$. There was no increase in the control group.

Effortful swallow training combined with electrical stimulation increased the extent of the laryngeal excursion. This intervention can be used as a new treatment method in post-stroke patients with dysphagia.

All 75 participants were drinking thin liquids and eating food successfully 12 to 24 hours after passing a 90 -cc water swallow challenge. The mean volume of liquid ingested was $385.4 \mathrm{cc}$, and the percent of diet eaten ranged from $10 \%$ to $100 \%$. Flowsheets indicated that specific diet

15. Leder SB, Suiter DM, Warner HL, Acton LM, single group consecutively Swainson BA series design 75 acute adult stroke patient - 90-cc water swallow challenge recommendations were followed with $100 \%$ accuracy.

Recommending specific oral diets to acute stroke patients based on passing 90-cc water swallow challenge protocol was supported. A 90-cc challenge is an easily administered, highly reliable, cost-effective, and validated clinical assessment that can be used by a variety of qualifi ed health care professionals to identify aspiration risk. When a 90-cc challenge protocol is passed, specifi c diet recommendations can be made safely and confi gently without the need for further objective dysphagia testing In this study, we found that inpatient Speech-Language pathologists (SLP) dysphagia therapy recommendations were frequently omitted from the discharge summaries of subacute care patients at high risk for aspiration pneumonia. Nondietary requests were omitted at the highest rates, in some categories nearing $80-100 \%$, while dietary recommendations were omitted for nearly half of all patients. To our knowledge, this is the first study to examine and report on deficiencies in dysphagia therapy communication at the time of hospital discharge.
Anderson P,

Hind J,

Retrospective

Robbins J,

cohort study

(2011)
159 patients with stroke and 28 patients a primary diagnosis of hip fracture
The omission of dysphagia therapies

in hospital

discharge

communications

Discharge summaries omitted all categories of SLP recommendations at notably high rates. Improved posthospital communication strategies are needed for discharges to subacute care

Although this screening is the task of speech and language therapy, since the nurse supervises the patient for 24 hours, the nurse is ideal for detecting simple dysphagia by paying attention to the level of awareness and following it. Commands control salivation, facial weakness, voice, speech, coughing, or voice changes after swallowing. ${ }^{24}$ Dysphagia screening is carefully evaluated through clinical history with the following question of swallowing disorders: What happens when you try to swallow? Do you have trouble chewing food? Do you have difficulty swallowing solid, liquid, or both foods? symptoms and frequency?, what are the symptoms you are experiencing today $?^{25}$

Nurses are in an ideal position for dysphagia screening as they are available 24 hours a day in the hospital; early intervention can prevent further complications. However, due to the nurses lack of knowledge about the advantages and skills surrounding dysphagia management, they did not conduct dysphagia screening. ${ }^{26}$

Based on research, nurses can do dysphagia screening 25 that $80 \%$ can screen for dysphagia and make proper referrals to nutritionists and language and speech therapists. The sensitivity and specificity of nurses in screening dysphagia is $89 \%-90 \% .^{27}$

The tools used for dysphagia screening vary depending on the analysis at the health institution (hospital). Some of the tools used for dysphagia screening include The Modified Mann Assessment of Swallowing Ability27; Barnes-Jewish Hospital Stroke Center (BJHSC) Acute Stroke Dysphagia screen $^{28}$; The Dysphagia Assessment Risk Tool (DART) ${ }^{24}$; Mann Assessment of Swallowing Ability (MASA) ${ }^{29}$; The

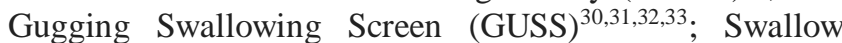
Frequency Analysis (SFA) ${ }^{34}$; The Toronto Bedside Swallowing Screening Test (TOR-BSST) ${ }^{28,35}$; Standardized Swallowing Assessment (SSA) ${ }^{36}$; Brief Bedside Dysphagia Screening Test (BBDST) $)^{36}$; The Massey Bedside Swallowing Screen. ${ }^{37}$ Significant predictor for aspiration is dysatria and cough after swallowing water is an independent predictor of aspiration which can be detected by SSA. ${ }^{38}$

\section{Oral care}

Pneumonia is a severe aspiration and can be a fatal complication of oropharyngeal dysphagia. To prevent this, regular and regular oral care can reduce aspiration pneumonia in patients with oropharyngeal dysphagia. ${ }^{10}$ Other research on oral health programs, if administered before ingestion treatment, may improve oral health outcomes and help maintain oral intake of stroke patients with dysphagia. ${ }^{11}$

\section{Chewing gum-based thickener xanthan}

This method has been widely researched namely the use of Resource ThickenUp Clear (RTUC) with results; increased ingestion safety indicated by decreased prevalence of cough and voice changes in clinical stuf as well as penetration and aspiration during fluoroscopy video surveillance; not improved residual peeling; viscosity does not affect bolus speed or ingestion response time. ${ }^{39}$ 
This is supported by the guidelines of viscous liquid criteria for the handling of dysphagia in Japan. Watanabe et al. (2018) explains that interventions with this thickener are suitable for cases of post-stroke dysphagia, even in cases where the risk of aspiration with a sufficiently viscous liquid can be consumed safely, although the medical team should assess viscosity and adhesion of the liquid to ensure safety during the swallowing process. ${ }^{39}$

Another study on the effect of gum-based thickeners on the safety of swallowing oropharyngeal dysphagia patients post-stroke obtained the result that bolus viscosity using thickeners cause a strong viscosity effect and improve the safety of swallowing without adding residue in the pharynx, this may be due to the specific effect on oropharyngeal physiology especially the time to shorten the time to close the pharyngeal space (laryngeal vestibule closure / LVC) and bolus speed. ${ }^{39}$

In contrast to the results of the review by Rainer (2016), the modification of the texture of food with viscous liquids with different consistencies aims to slow down the swallowing process so that it is safer. However, there is slight preference or study on the effectiveness of preventing or reducing the impact of dysphagia on patients for texturemodified foods or viscous liquids compared to regular foods. The results of studies on foods with a lower or higher viscosity than honey can significantly increase the risk of aspiration, making it essential to use standardized thickeners. $^{41}$

In determining food texture modification should pay attention to characteristics that affect swallowing mechanisms such as food texture, density, hardness, and cunning. ${ }^{42}$ Besides, a diet that promises fat and rich energy is needed with a sweet and sour taste and cold or freezing temperatures depending on the patient's type to offer the diet to patients with dysphagia. ${ }^{43}$ Differing from research on the disconnection between a limited evidence base and widespread use of modified diets suggests the need for more careful consideration of when a modified diet might be recommended to patients. Patients (or their representatives) have a choice whether or not to accept a modified diet and should receive adequate information about the potential risks and their impact on the quality of life and possible benefits to make that choice. There is an urgent need for better quality evidence of this intervention. ${ }^{13}$

\section{Laryngeal elevation exercises}

Laryngeal elevation exercises are called the Maneuver Swallow and Mendelsohn maneuvers, which are swallowing attempts combined with Mendelsohn maneuvers. The patient is asked to follow the instructions, "when you swallow, squeeze as hard as possible with all the muscles of the throat". Then while still squeezing the muscles of the throat and holding the larynx at its highest point. Do not let food fall down your throat and hold for about 1 second". ${ }^{44}$ These results suggest that non-invasive oral neuromuscular training is a promising new rehabilitation method for swallowing dysfunction. The discovery is the first step to obtaining evidence about training methods among individuals with swallowing disorders. ${ }^{19}$
The experiment results were obtained after this exercise; the rate of installation of the nasogastric tube was $100 \%$, after therapy $80 \%$ of the experimental group and $20 \%$ in the control group after 16 sessions of treatment. The positive effect of this therapy is the presence of hyoid bone movement that can increase, which results in a decrease in the classification level of dysphagia as measured by the Functional Oral Intake Scale (FOIS). ${ }^{44}$

This is supported by research that Mendelsohn maneuvers will extend the duration of the esophageal spout's opening by extending the larynx's elevation over a long period during swallowing. With this exercise, there will be a physiological improvement in swallowing in people with dysphagia. ${ }^{45}$ In other interventions with Expiratory Muscle Strength Training (EMST) may increase dysphagia's poststroke effect based on swallowing function. ${ }^{46}$ Other devices can be used for maintenance and increase oropharyngeal intake, improve ingestion safety and facilitate the opening of the upper esophageal sphincter (UES) while enriching QOL. ${ }^{4}$

Currently under testing is the effectiveness of comparison between tongue strength resistance training and tongue pressure accuracy with tongue pressure profile training as a standard of care and best practice for patients with dysphagia involving impaired fluid control due to stroke. 18 In addition, exercise in the case of neurology can also prevent cognitive decline and ability, and this is related to the process of neurogenesis involving the role of neurotrophic factors that will increase after exercise. ${ }^{47}$

\section{Peripheral Stimulation}

Although the efficacy of this therapy is controversial, some simple techniques have been used in dysphagia patients to increase pressure on the tongue with a spoon during meals or use acid bolus (filled with lemon juice) to stimulate swallowing, in the hope that this intervention can stimulate swallowing: Bitter taste and the base of the tongue to increase the retraction of the tongue, soft palate to increase laryngeal height, superior and medial pharyngeal constrictor muscles to improve faring peristaltik and UES opening. ${ }^{22}$ Other interventions in surface electrical stimulation combined with ingestion efforts as a form of endurance training increased laryngeal excursion rates in post-stroke patients with dysphagia. ${ }^{20}$

Other studies relating to the role of peripheral reflexes in the swallowing phase in the esophagus conducted in animals try to explain that peripheral reflexes through the bolus indicate the start of the oesophageal phase, which is related to the size of the passing bolus. Esophagus and have different times in terms of muscle response in the pharynx phase. $^{39}$

\section{Postural adjustments}

Posture adjustment is performed on the head and neck during swallowing. It can be effective even if not in all patients, namely by turning the head to the weak side and tilting to the strong side when taking medication or swallowing. ${ }^{48}$ Some interventions in the regulation of posture, among others: Oblique head is indicated due to inability to control the tongue and unilateral pharyngeal weakness; Chin Tuck is indicated for delayed pharynx swallowing response; and Head Rotation that shows unilateral pharynx weakness. ${ }^{22}$ 
Research conducted on the effect of chin tuck on swallowing function in post-stroke dysphagia patients showed that there was an increase in swallowing in terms of oral cavity repair, increased epiglottis, and residues in valleculae compared to the control group (p. <0.05), this can be explained because; Chin Tuck Tuck is a sport/gymnastics that exerts much weight on the target muscle, and suprahyoid muscle activity is enhanced because when suprahyoid muscles contract it helps the condition of the formation of the pharynx bolus and helps the epiglottis to close the upper airway. ${ }^{49}$

The approach to changes in posture (chin tuck maneuver, supraglottic swallow) and the use of viscous fluids such as nectar and honey can help dysphagia patients, but the effects vary and are difficult to do if the patient has dementia. ${ }^{50}$

Tilt the head, and head rotation is applied to dysphagia patients whose food remains on the paralyzed side due to unilateral weakness of the mouth or pharynx. When the head is tilted, food flows towards the tilted head. This position will make the food enter slowly into the pharynx and increase the pressure on the pharynx. ${ }^{51}$

In other studies, it was explained that eating with a sitting position above the pelvis and putting the foot on the surface allows the patient to have stable tongue pressure while eating, or at severe dysphagia Fowler's position is considered an influential position. ${ }^{52}$ Experimental treatment with the patient is positioned in a lying position tilted, half sitting, or sitting, depending on which position optimizes the patient's ability to swallow pumping jaw movement frequency during a decreased intervention. These results seem to reflect the clinical experience of ingestion facilitation, and therefore this action appears to be valid in measuring ingesting kinematics on a non-invasive basis. ${ }^{21}$

\section{Educate on how to eat and drink}

Early treatment of stroke is essential to prevent advanced complications of dysphagia related to nutrition. According to research, good nutritional status affects the percentage of good clinical outcomes, although there is no difference in nutritional status (normal, trimmer, and more) with the clinical outcome of acute-phase stroke patients. ${ }^{53}$

Nutritional status affects patient health, as research suggests (2021), good nutritional status affects the percentage of good clinical outcomes. However, there is no difference in nutritional status (average, trimmer, and more) with the clinical outcomes of acute-phase stroke patients

The key to managing dysphagia is optimizing the swallowing process, encouraging a safe swallowing process, and providing liquid food with the appropriate texture. Education provided on how to eat and drink, include: sit upright 90 degrees when eating and drinking, do not eat and drink at the time of bending or sleeping, eat a little food, drink a little fluid; do not swallow drinks, eat slowly and chew food well before swallowing, make sure you have consumed your food or drink before taking more, do not wash food with drinks, do not speak when you have food in your mouth. ${ }^{54}$

Dysphagia education involves all components of the nursing staff. It requires continuous innovation to be consistent with implementations that require national quality regulations and standards to identify people with difficulty swallowing, and appropriate action is required.55 Nurses should educate patients about assessing food and drink needs, and nurses are responsible for ongoing nasogastric installation and care, including referrals to nutritionists if necessary. ${ }^{3}$ Research by Leder et al. (2012) challenges $90 \mathrm{cc}$ is an easy-to-provide, highly reliable, costeffective, and validated clinical assessment that can be used by a wide range of qualified healthcare professionals to identify aspirational risks. When the $90 \mathrm{cc}$ challenge protocol is passed, unique dietary recommendations can be made safely and definitively without the need for more objective dysphagia testing. In contrast to Kind et al. (2011) research, dietary recommendations were eliminated at the highest level, in some categories close to $80-100 \%$, while dietary recommendations were eliminated for almost half of all patients.

\section{Conclusion}

There are a variety of different interventions performed in patients with post-stroke dysphagia in hospitals. While not diagnosing dysphagia, nurses can informally determine post-stroke patients who experience dysphagia in determining the interventions necessary for nutrition management, hydration, and aspiration prevention.

Interventions that nurses can make in post-stroke dysphagia include early dysphagia screening within 24 hours after stroke, thickening nutrition according to the advice of nutritionists, laryngeal elevation gymnastics, peripheral stimulation, posture adjustment, education on how to eat and drink. There are health promotional interventions that nurses can use to improve patient and family knowledge through education on eating and drinking for people with post-stroke dysphagia.

\section{Conflict of Interest}

The authors declare that there is no conflict of interest

\section{Acknowledgement}

We would like to thank the reviewers for their helpful comments and suggestions to improve our study. We also thank the Master Nursing Faculty of Medicine, Brawijaya University for their support.

\section{References}

1. Chen DF. Dysphagia in the hospitalized patient. Hosp Med Clin [Internet]; 2017. 6(1):38-52.

DOI: 10.1016/j.ehmc.2016.07.004

2. Al-Khaled M, Matthis C, Binder A, Mudter J, Schattschneider J, Pulkowski U, et al. Dysphagia in patients with acute ischemic stroke: Early dysphagia screening may reduce stroke-related pneumonia and improve stroke outcomes. Cerebrovasc Dis; 2016. 42(1-2):81-9. DOI: 10.1159/000445299

3. Clare CS. Role of the nurse in stroke rehabilitation. Nurs Stand (Royal Coll Nursing) (Great Britain) 1987) [Internet]; 2018;33(7):59-66. Available from: https://search.proquest.com/docview/2131313019/fullt ext/201256D3E4684619PQ/1?accountid=46437

4. Juan J, Hind J, Jones C, McCulloch T, Gangnon R, Robbins J. Case study: Application of isometric 
progressive resistance oropharyngeal therapy using the madison oral strengthening therapeutic device. Top Stroke Rehabil [Internet]; 2013. 20(5):450-70. Available from: http://web.b.ebscohost.com.ub.remotexs.co/ehost/detai $1 /$ detail? vid $=6 \&$ sid $=9563 \mathrm{cc} 2 \mathrm{f}-2564-43 \mathrm{fO}-82 \mathrm{e} 2-$ 390d147d6293\%40sessionmgr101\&bdata=JnNpdGU9 ZWhvc3QtbGl2ZQ\%3D\%3D\#db=mdc\&AN=240912 87

5. Hines S, Kynoch K, Munday J. Identification and nursing management of dysphagia in individuals with acute neurological impairment: A systematic review protocol. JBI Database Syst Rev Implement Reports; 2013. 11(7):312-23.

6. Rachmawati D, Ningsih DK, Andarini S. Factors affecting the knowledge about stroke risks and early symptoms in emergency department East Java Indonesia. MNJ (Malang Neurology Journal); 2020. 6(1):11-9. DOI: 10.21776/ub.mnj.2020.006.01.3

7. Geeganage $\mathrm{C}$, Beavan J, Ellender S, Bath PM. Interventions for dysphagia and nutritional support in acute and subacute stroke. Cochrane Database Syst Rev; 2012. (10).

DOI: 10.1002/14651858.CD000323.pub2

8. PPNI. Standar intervensi keperawatan Indonesia: Definisi dan tindakan keperawatan. 1st ed. Jakarta, Indonesia: DPP PPNI; 2018.

9. Hines S, Kynoch K, Munday J. Nursing interventions for identifying and managing acute dysphagia are effective for improving patient outcomes: A systematic review update. J Neurosci Nurs; 2016. 48(4):215-23. DOI: 10.1097/JNN.0000000000000200

10. Seedat J, Penn C. Implementing oral care to reduce aspiration pneumonia amongst patients with dysphagia in a South African setting. South African J Commun Disord = Die Suid-Afrikaanse Tydskr vir Kommun [Internet]; 2016. 63(1):1-12. Available from:

http://web.b.ebscohost.com.ub.remotexs.co/ehost/pdfv iewer/pdfviewer?vid=0\&sid=17ea7dc9-0f2c-40c08fd2-75fdb1710cb9\%40pdc-v-sessmgr03

11. Chen HJ, Chen JL, Chen CY, Lee M, Chang WH, Huang TT. Effect of an oral health programme on oral health, oral intake, and nutrition in patients with stroke and dysphagia in taiwan: A randomised controlled trial. Int J Environ Res Public Health [Internet]; 2019. 16(12):1-13. Available from: http://web.b.ebscohost.com.ub.remotexs.co/ehost/detai 1/detail?vid=0\&sid=42fc17bb-d6d2-42a2-bd9a2bb3cb638783\%40pdc-vsessmgr01\&bdata=JnNpdGU9ZWhvc3QtbG12ZQ\%3 D\%3D\#AN=31238591\&db=mdc

12. Clave, Lansink, Bolivar-Prados, Mireia Laia Rofes, Viridiana Arreola, Sonia Guida, Weslania V. Nascimento et al. Effect of a gum-based thickener on the safety of swallowing in patients with poststroke oropharyngeal dysphagia. Neurogastroenterol Motil; 2019. 31(11):1-11. DOI: 10.1111/nmo.13695

13. O'Keeffe ST. Use of modified diets to prevent aspiration in oropharyngeal dysphagia: Is current practice justified? Vol. 18, BMC Geriatrics; 2018. Avalaible from: https://bmcgeriatr.biomedcentral.com/articles/10.1186 /s12877-018-0839-7

14. Andersen UT, Beck AM, Kjaersgaard A, Hansen T, Poulsen I. Systematic review and evidence based recommendations on texture modified foods and thickened fluids for adults $(\geq 18$ years $)$ with oropharyngeal dysphagia. ESPEN J [Internet]; 2013. 8(4):e127-34. DOI: 10.1016/j.clnme.2013.05.003

15. Leder SB, Suiter DM, Warner HL, Acton LM, Swainson BA. Success of recommending oral diets in acute stroke patients based on passing a 90-cc water swallow challenge protocol. Top Stroke Rehabil [Internet]; 2012;19(1):40-4. Available from: http://web.b.ebscohost.com.ub.remotexs.co/ehost/detai 1/detail?vid=0\&sid=bff8567b-d7ac-4e5d-965b47c867948ac4\%40sessionmgr 103\&bdata=JnNpdGU9 ZWhvc3QtbGl2ZQ\%3D\%3D\#AN=22306627\&db=m dc

16. Yu Zhang Xudong Jiang ZW. Comparative efficacy of non-pharmaceutical therapy in the treatment of dysphagia after stroke: A Bayesian network metaanalysis. Medicine (Baltimore); 2020. 99(9):1-5.

17. Hwang NK, Kim HH, Shim JM, Park JS. Tongue stretching exercises improve tongue motility and oromotor function in patients with dysphagia after stroke: A preliminary randomized controlled trial. Arch Oral Biol [Internet]; 2019. 108(August):104521. DOI: 10.1016/j.archoralbio.2019.104521

18. Steele CM, Bayley MT, Peladeau-Pigeon M, Nagy A, Namasivayam AM, Stokely SL, et al. A randomized trial comparing two tongue-pressure resistance training protocols for post-stroke dysphagia. Dysphagia; 2016. 31(3):452-61.

DOI: $10.1007 / \mathrm{s} 00455-016-9699-5$

19. Hägglund $P$, Hägg $M$, Wester $P$, Levring Jäghagen E. Effects of oral neuromuscular training on swallowing dysfunction among older people in intermediate care A cluster randomised, controlled trial. Age Ageing [Internet]; 2019. 48(4):533-40. Available from: http://web.b.ebscohost.com.ub.remotexs.co/ehost/pdfv iewer/pdfviewer?vid=1\&sid=5c8f8dc1-e7fc-4c188430-fdf0d4c9b019\%40pdc-v-sessmgr06

20. Park JW, Kim Y, Oh JC, Lee HJ. Effortful swallowing training combined with electrical stimulation in poststroke dysphagia: A randomized controlled study. Dysphagia [Internet]; 2012. 27(4):521-7. Available from:

http://web.b.ebscohost.com.ub.remotexs.co/ehost/detai 1/detail?vid=0\&sid=b43b4ceb-12d1-4064-9056dc2eb043a8c3\%40pdc-vsessmgr04\&bdata=JnNpdGU9ZWhvc3QtbG12ZQ\%3 $\mathrm{D} \% 3 \mathrm{D} \# \mathrm{db}=\mathrm{mdc} \& \mathrm{AN}=22447240$

21. Jakobsen D, Poulsen I, Schultheiss C, Riberholt CG, Curtis DJ, Petersen TH, et al. The effect of intensified nonverbal facilitation of swallowing on dysphagia after severe acquired brain injury: A randomised controlled pilot study. NeuroRehabilitation; 2019. 45(4):525-36. DOI: 10.3233/NRE-192901

22. Rainer wirth, Rainer Dziewas, Anne Marie Beck, Pere Clavé SHHJH et al. Oropharyngeal dysphagia in older persons - from pathophysiology to adequate intervention: A review and summary of an 
international expert meeting. Clin Interv Aging; 2016. 11:189-208. DOI: 10.2147/CIA.S97481

23. Hughes SM. Management of dysphagia in stroke patients. Nurs Older People (through 2013) [Internet]; 2011. 23(1):21-4. Available from: https://search.proquest.com/docview/860038578/abstr act/2AFED978C66C4A60PQ/1 ?accountid=46437

24. Murray, J, Milich, A, \& Ormerod D. Screening for dysphagia: ANJ. Australian Nursing Journal. Aust Nurs J [Internet]; 2011;18(11):44-6. Available from: https://search.proquest.com/docview/871417361?acco untid $=46437$

25. Jansson-Knodell CL, Codipilly DC, Leggett CL. Making dysphagia easier to swallow: A review for the practicing clinician. Mayo Clin Proc [Internet]; 2017. 92(6):965-72. DOI: 10.1016/j.mayocp.2017.03.021

26. Liu H, Shi Y, Shi Y, Hu R, Jiang H. Nursing management of post-stroke dysphagia in a tertiary hospital: A best practice implementation project. JBI database Syst Rev Implement reports.; 2016. 14(7):266-74. DOI: 10.11124/JBISRIR-2016-002971

27. Cummings J, Soomans D, O'Laughlin J, Snapp V, Jodoin A. Sensitivity and specificity of a nurse dysphagia screen in stroke patients. Medsurg Nurs [Internet]; 2015;24(4):219-22. Available from: https://search.proquest.com/docview/1705664144?acc ountid $=46437$

28. Edmiaston J, Connor LT, Loehr L, Nassief A. Validation of a dysphagia screening tool in acute stroke patients. Am J Crit Care; 2010. 19(4):357-64. DOI: $10.4037 /$ ajcc2009961

29. Titsworth LW, Abram J, Fullerton A, Hester J, Guin $\mathrm{P}$, Michael $\mathrm{f}$ et al. Prospective quality initiative to maximize dysphagia screening reduces hospitalacquired pneumonia prevalence in patients with stroke. Stroke [Internet]; 2013. 44(11):3154-60. Available

from: https://www.ahajournals.org/doi/10.1161/STROKEA HA.111.000204?url_ver=Z39.88-

2003\&rfr_id=ori:rid:crossref.org\&rfr_dat $=$ cr_pub Opubmed

30. Sørensen RT, Rasmussen RS, Overgaard K, Lerche A, Johansen AM, Lindhardt T. Dysphagia screening and intensified oral hygiene reduce pneumonia after stroke. J Neurosci Nurs; 2013. 45(3):139-46. DOI: 10.1097/JNN.0b013e31828a412c

31. Palli C, Fandler S, Doppelhofer K, Niederkorn K, Enzinger C, Vetta C, et al. Early dysphagia screening by trained nurses reduces pneumonia rate in stroke patients: A clinical intervention study. Stroke [Internet]; 2017;48(9):2583-5. Available from: https://www.ahajournals.org/doi/10.1161/STROKEA HA.117.018157?url_ver=Z39.88-

2003\&rfr_id=ori:rid:crossref.org\&rfr_dat $=$ cr_pub Opubmed

32. Benfield JK, Everton LF, Bath PM, England TJ. Accuracy and clinical utility of comprehensive dysphagia screening assessments in acute stroke: A systematic review and meta-analysis. J Clin Nurs; 2020. 29(9-10):1527-38. DOI: 10.1111/jocn.15192

33. St. John J, Berger L. Using the gugging swallowing screen (GUSS) for dysphagia screening in acute stroke patients. J Contin Educ Nurs; 2015. 46(3):103-4. DOI: $10.3928 / 00220124-20150220-12$

34. Crary MA, Carnaby GD, Sia I. Spontaneous swallow frequency compared with clinical screening in the identification of dysphagia in acute stroke. J Stroke Cerebrovasc Dis [Internet]; 2014. 23(8):2047-53. DOI: 10.1016/j.jstrokecerebrovasdis.2014.03.008

35. Martino R, Maki E, Diamant N. Identification of dysphagia using the Toronto Bedside Swallowing Screening Test (TOR-BSSTC): Are 10 teaspoons of water necessary? Int J Speech Lang Pathol [Internet]; 2014. 16(3):193-8. Available from: https://www.researchgate.net/publication/262381399_ Identification_of_dysphagia_using_the_Toronto_Beds ide_Swallowing_Screening_Test_TOR-

BSSTC_Are_10_teaspoons_of_water_necessary

36. Jiin, Ling Jiang, Shu, Ying Fu, Wan, Hsiang Wang, $\mathrm{Yu}$ CM. Validity and reliability of swallowing screening tools used by nurses for dysphagia: A systematic review. Tzu Chi Med J [Internet]; 2016. 28(2):41-8. Available from: https://www.sciencedirect.com/science/article/pii/S10 16319016300088

37. Wangen T, Hatlevig J, Pifer G VK. Preventing aspiration complications: Implementing a swallow screening tool. Clin Nurse Spec; 2019. 33(5):237-43. DOI: 10.1097/NUR.0000000000000471

38. Lindner-Pfleghar B, Neugebauer H, Stösser S, Kassubek J, Ludolph A, Dziewas R, et al. Management of dysphagia in acute stroke: A prospective study for validation of current recommendations. Nervenarzt; 2017;88(2):173-9. DOI: $10.1007 / \mathrm{s} 00115-016-0271-1$

39. Rofes L, Arreola V, Mukherjee R, Swanson J, Clave P et al. The effects of a xanthan gum-based thickener on the swallowing function of patients with dysphagia. Aliment Pharmacol Ther; 2014. 39(10):1169-79. DOI: 10.1111/apt.12696

40. Watanabe E, Yamagata Y, Fujitani J, Fujishima I, Takahashi K, Uyama R, et al. The criteria of thickened liquid for dysphagia management in japan. Dysphagia; 2018. 33(1):26-32. DOI: 10.1007/s00455-017-9827-X

41. Li M, Wang Z, Han W-J, Lu S-Y, Fang Y-Z. Effect of feeding management on aspiration pneumonia in elderly patients with dysphagia. Chinese Nurs Res [Internet]; 2015;2(2-3):40-4.

DOI: $10.1016 /$ j.cnre.2015.09.004

42. Beck AM, Kjaersgaard A, Hansen T, Poulsen I. Systematic review and evidence based recommendations on texture modified foods and thickened liquids for adults (above 17 years) with oropharyngeal dysphagia - An updated clinical guideline. Clin Nutr [Internet]; 2018;37(6):1980-91. DOI: 10.1016/j.clnu.2017.09.002

43. Okkels SL, Saxosen M, Bügel S, Olsen A, Klausen TW, Beck AM. Acceptance of texture-modified inbetween-meals among old adults with dysphagia. Clin Nutr ESPEN [Internet]; 2018;25:126-32.

DOI: $10.1016 /$ j.clnesp.2018.03.119

44. Li CM, Wang TG, Lee HY, Wang HP, Hsieh SH, Chou M, et al. Swallowing training combined with game-based biofeedback in poststroke dysphagia. PM R [Internet]; 2016.2 8(8):773-9. 
DOI: 10.1016/j.pmrj.2016.01.003

45. McCullough GH, Kim Y. Effects of the mendelsohn maneuver on extent of hyoid movement and UES opening post-stroke. Dysphagia; 2013. 28(4):511-9. DOI: $10.1007 / \mathrm{s} 00455-013-9461-1$

46. Eom MJ, Chang MY, Oh DH, Kim HD, Han NM, Park JS. Effects of resistance expiratory muscle strength training in elderly patients with dysphagic stroke. NeuroRehabilitation [Internet]; 2017. 41(4):747-52. Available from: http://web.b.ebscohost.com.ub.remotexs.co/ehost/detai 1/detail?vid=0\&sid=5b8251a3-54cb-4bb9-a865d8631700e522\%40pdc-vsessmgr04\&bdata=JnNpdGU9ZWhvc3QtbGl2ZQ\%3 $\mathrm{D} \% 3 \mathrm{D} \# \mathrm{db}=\mathrm{mdc} \& \mathrm{AN}=29254116$

47. Rivarti AW, Herawati L, Hidayati HB. Exercise prevents age-related memory decline: The role of neurotrophic factors. MNJ (Malang Neurol Journal) [Internet]; 2020. 6(2):88-94. Available from: https://mnj.ub.ac.id/index.php/mnj/article/view/440/42 8

48. Chang, Robert MM MW. Advances in the management of dysphagia caused by stroke. Physical Med Rehabil Clin North Am; 1999. 10(4):925-41. Avalaible from: https://pubmed.ncbi.nlm.nih.gov/10573716/

49. Park JS, An DH, Oh DH, Chang MY. Effect of chin tuck against resistance exercise on patients with dysphagia following stroke: A randomized pilot study. NeuroRehabilitation; 2018;42(2):191-7. DOI: $10.3233 / \mathrm{NRE}-172250$

50. Alagiakrishnan K, Bhanji RA, Kurian M. Evaluation and management of oropharyngeal dysphagia in different types of dementia: A systematic review. Arch Gerontol Geriatr [Internet]; 2013. 56(1):1-9. DOI: 10.1016/j.archger.2012.04.011
51. Kim CK, Ryu JS, Song SH, Koo JH, Lee KD, Park HS, et al. Effects of head rotation and head tilt on pharyngeal pressure events using high resolution manometry. Ann Rehabil Med; 2015. 39(3):425-31. DOI: 10.5535/arm.2015.39.3.425

52. Yoshikawa M, Nagakawa K, Tanaka R, Yamawaki K, Mori T, Hiraoka A, et al. Improper sitting posture while eating adversely affects maximum tongue pressure. J Dent Sci [Internet]; 2020. (xxxx):1-2. DOI: $10.1016 /$ j.jds.2020.08.012

53. Junaidi et al. Perbedaan tingkat status gizi dengan luaran klinis pasien stroke iskemik fase akut di RSUD Dr. Saiful Anwar Malang. Malang Neurol J [Internet]; 2017. 3(1):17-22. Available from: https://mnj.ub.ac.id/index.php/mnj/article/view/247

54. Nazarko L. The management of dysphagia in palliative care. Int J Palliat Nurs; 2017. 23(4):162-4. DOI: 10.12968/ijpn.2017.23.4.162

55. Ilott I, Gerrish K, Pownall S, Eltringham S, Booth A. Exploring scale-up, spread, and sustainability: An instrumental case study tracing an innovation to enhance dysphagia care. Implement Sci; 2013;8(1):18. Avalaible from: https://implementationscience.biomedcentral.com/arti cles/10.1186/1748-5908-8-128

56. Kind A, Anderson P, Hind J, Robbins JA, Smith M. Omission of dysphagia therapies in hospital discharge communications. Dysphagia [Internet]; 2011. 26(1):49-61. Available from: http://web.b.ebscohost.com.ub.remotexs.co/ehost/detai 1/detail?vid=0\&sid=099359d9-b1b6-493b-9565a067582fb29e\%40pdc-vsessmgr06\&bdata=JnNpdGU9ZWhvc3QtbGl2ZQ\%3 $\mathrm{D} \% 3 \mathrm{D} \# \mathrm{db}=\mathrm{mdc} \& \mathrm{AN}=20098999$ 